\title{
Article \\ Degradation of Acid Red 1 Catalyzed by Peroxidase Activity of Iron Oxide Nanoparticles and Detected by SERS
}

\author{
Edna Vázquez-Vélez *(D, Horacio Martínez * and Fermín Castillo \\ Instituto de Ciencias Físicas, Universidad Nacional Autónoma de México. Av. Universidad 1000, \\ Col. Chamilpa, 62210 Cuernvaca, Morelos, Mexico; ciro@icf.unam.mx \\ * Correspondence: velez.edna@icf.unam.mx (E.V.-V.); hm@icf.unam.mx (H.M.)
}

Citation: Vázquez-Vélez, E.; Martínez, H.; Castillo, F. Degradation of Acid Red 1 Catalyzed by Peroxidase Activity of Iron Oxide Nanoparticles and Detected by SERS. Nanomaterials 2021, 11, 3044. https:// doi.org/10.3390/nano11113044

Academic Editors: Jihoon Lee and Ming-Yu Li

Received: 1 October 2021

Accepted: 3 November 2021

Published: 12 November 2021

Publisher's Note: MDPI stays neutral with regard to jurisdictional claims in published maps and institutional affiliations.

Copyright: (C) 2021 by the authors. Licensee MDPI, Basel, Switzerland. This article is an open access article distributed under the terms and conditions of the Creative Commons Attribution (CC BY) license (https:// creativecommons.org/licenses/by/ $4.0 /)$.

\begin{abstract}
Magnetic iron oxide nanoparticles (MIONPs) were synthesized using tannic acid and characterized by Raman, FTIR, UV, and DRX spectroscopy. In a heterogeneous Fenton-like reaction, the catalytic peroxidase-like activity of MIONPs in the degradation of Acid Red 1 (AR 1) dye was investigated. TEM/STEM was used to determine the quasi-spherical morphology and particle size $(3.2 \mathrm{~nm})$ of the synthesized MIONPs. The XRD powder patterns were indexed according to the reverse spinel structure of magnetite, and SEM-EDS analysis confirmed their chemical composition. At $\mathrm{pH}=3.5$, the decomposition of $\mathrm{H}_{2} \mathrm{O}_{2}$ in hydroxyl radicals by MIONPs results in high AR 1 degradation $(99 \%)$. This behavior was attributed to the size and surface properties of the MIONPs. Finally, the Surface Enhanced Raman Spectroscopy (SERS) technique detected intermediary compounds in the degradation process.
\end{abstract}

Keywords: magnetite; peroxidase activity; SERS

\section{Introduction}

The textile industry represents two-thirds of the use of dyes resulting in one of the main sources of contamination. Due to the high concentration of dye in the wastewater from these installations, it is not easy to treat it satisfactorily. It is estimated that $2 \%$ of the colorants are discharged directly into the aqueous effluent [1]. Azo-type dyes are the most commonly used polluting compounds, accounting for $70 \%$ of the total. Notably, the acid red 1 (AR 1) dye is among the 11 non-biodegradable azo compounds listed [2]. Nowadays, the importance of this type of dye increases in the field of biomedicine, electronics, and energy because dyes can absorb visible electromagnetic radiation with high efficiency. As a result, removing the non-biodegradable dye is a significant environmental issue. These compounds can be found in the aquatic environment, and they are poisonous to both marine and human organisms. Besides, they are mutagenic and carcinogenic [3]. For decades, there has been a growing interest in removing these difficult-to-remove compounds [4,5]. However, new technology is required to complete the mineralization of various dyes while minimizing their impact on the environment and humans.

Nanotechnology is one of the fastest-growing and emerging research areas today. Problems related to water quality can be solved or improved through it. The synthesis of nanoparticles is an economical, effective, efficient, and sustainable alternative. Its use makes treatment processes less polluting than traditional methods [6,7]. In recent decades, magnetic iron oxide nanoparticles (MIONPs) have sparked interest in catalytic wet peroxide oxidation (CWPO) or Fenton heterogeneous oxidation. The potential of these materials stems from their more remarkable ability to degrade recalcitrant contaminants, which involves the generation of hydroxyl radicals in sufficient quantities to allow oxidation $[8,9]$. The hydroxyl radical constitutes one of the most powerful oxidants $(\mathrm{E} 0=2.73 \mathrm{~V})$, and is much stronger than other conventional oxidizing species such as hydrogen peroxide $(\mathrm{E} 0=1.31 \mathrm{~V})$ or ozone $(\mathrm{E} 0=1.52 \mathrm{~V})[10]$. MIONPs represent a promising alternative to the conventional catalysts used in CWPO due to their higher activity, easy recovery, and 
further reusability. In this context, one of the most critical challenges in CWPO is the development of more active and stable catalysts. Several studies on the degradation of recalcitrant dyes using MIONPs have been published [10]. Iron oxide nanoparticles have also been supported on various porous materials to improve their efficiency in heterogeneous Fenton-like catalysis [11]. Other studies have used ultrasonic radiation to improve the degradation efficiency of dyes [12]. The peroxidase-like activity of magnetite nanoparticles to generate hydroxyl radicals, in particular, has been extensively studied in the degradation of molecules [13]. However, its study on the degradation of recalcitrant contaminants continues to be of great interest due to being one of the most cost-effective CWPO.

This work describes an accessible synthesis of magnetic iron oxide nanoparticles (MIONPs) utilizing tannic acid, a water-soluble polyphenol frequently found in herbaceous and woody plants [14]. Furthermore, the peroxidase-like activity of synthesized MIONPs in the oxidative degradation of acid red 1 dye was investigated. The quantification of hydrogen peroxide generation confirmed that AR 1 was degraded by hydroxyl radicals. Finally, the SERS technique was used to characterize the intermediate compounds in the degradation process.

\section{Materials and Methods}

\subsection{Materials}

All chemical reagents and solvents were purchased from Merck KGaA, Darmstadt, Germany. Deionized water Millipore was used for NPs formation, and all degradation experiments were performed with ultrapure water. The acid red 1 solution was prepared fresh before each experiment to ensure the accuracy of the experimental data. The $\mathrm{pH}$ of the solution was adjusted using $\mathrm{NaOH}$ or $\mathrm{HCl}$ solution (5\%).

\subsection{Synthesis of MIONPS}

Magnetic Iron oxide nanoparticles (MIONPs) were synthesized by dissolving $0.8 \mathrm{~g}$ ( $3 \mathrm{mmol}$ ) of iron (III) chloride hexahydrate $\left(\mathrm{FeCl}_{3} \cdot 6 \mathrm{H}_{2} \mathrm{O}\right)$ in $20 \mathrm{~mL}$ of deionized water to which the capping agent was added: $0.25 \mathrm{~g}$ of tannic acid $(0.14 \mathrm{mmol})$ dissolved in $20 \mathrm{~mL}$ of deionized water. The solution immediately produces a black-colored solution, which was mechanically stirred at $250 \mathrm{rpm}$. The $\mathrm{pH}$ of the solution was then adjusted to $7.6 \pm 0.2$ by adding $\mathrm{NaOH}$ solution drop by drop. The result was the formation of a magnetic black precipitate. The solid was washed three times with deionized water $(40 \mathrm{~mL})$ to remove the salts, once with acetone to remove residual water, and three times with ethanol to eliminate the organic matter. All washes were accomplished with the assistance of an external magnetic field to separate the liquid from the solid. Finally, the black solid was dried at $80^{\circ} \mathrm{C}$ for two hours and used immediately for degradation tests.

\subsection{Characterization Techniques}

Morphological and size study of the nanoparticles was analyzed by field emission transmission electron microscopy (TEM/STEM, JEOL JEM-2010 FEG, Akishima, Tokyo, Japan) operating at $200 \mathrm{kV}$. A drop of the solution (NPs dispersed in EtOH) was placed on a carbon-coated copper grid to prepare the sample. Scanning electron microscopy (SEM) and energy-dispersive X-ray spectroscopy (EDS) was performed on MIONPs using a TESCAN MIRA 3 GMU microscope from Brno-Kohoutovice, Czech Republic; coupled with energy dispersive X-ray analysis (Brucker). A drop of the solution of NPs dispersed was placed on carbon tape to create the sample. The X-ray diffraction (XRD) patterns of the synthesized nanoparticles were recorded using a Rigaku Miniflex DMAX 2200 X-ray diffractometer, Austin, TX, USA. The solid was subjected to $\mathrm{Cu} \mathrm{K} \alpha$ radiation (1.54 ̊̊) with graphite monochromator in the $2 \theta$ range of $5-80^{\circ}$. For the characterization by UVvis spectrophotometry, the solid was dispersed in ethanol with the help of ultrasonic vibrations. The solution was analyzed using an Ocean View UV-vis spectrophotometer, Orlando, FL, USA. FTIR spectroscopy was used to characterize the nanoparticles using a Bruker ATR-FTIR spectrometer Alpha II, Ettlingen, Germany. Raman spectroscopy using a 
confocal microscope Raman Bruker SENTERRA II from Ettlingen, Germany, confirmed the composition and crystallographic phase of Iron NPs. A low laser power $(1 \mathrm{~mW})$ was used to avoid sample degradation due to laser heating. The accumulation time was 10,000 ms. Bleaching of $1 \mathrm{~mW}$ and $100 \mathrm{~ms}$ was performed to attenuate the fluorescence of the sample. A power of $25 \mathrm{~mW}$ and an integration time of $20,000 \mathrm{~ms}$ were used for the samples analyzed by the SERS technique.

\subsection{Degradation Procedure}

The $\mathrm{pH}$ effect on dye degradation was studied by adjusting the starting $\mathrm{pH}$ of the $\mathrm{AR}$ 1 solution at a concentration of $50 \mathrm{mg} / \mathrm{L}$. AR 1 solution was carried to a $\mathrm{pH}=3.5,4.5,6.5$, 8.5, and 10.5 using either solution of $\mathrm{HCl}$ or $\mathrm{NaOH}(5 \%)$. MIONPs $(2 \mathrm{~g} / \mathrm{L})$ were dispersed in AR 1 solution ( $50 \mathrm{~mL}$ ) using ultrasonic vibrations for $5 \mathrm{~s}$. A $2 \mathrm{mM}$ concentration of $\mathrm{H}_{2} \mathrm{O}_{2}$ was then added to begin heterogeneous Fenton-like catalysis. This amount was found to be the bare minimum required to initiate the peroxidase-like activity of MIONPs. The oxidation process was carried out in the absence of light. The absorbance was measured at $505.06 \mathrm{~nm}$ after $60 \mathrm{~min}$ of treatment. On the other hand, the degradation of AR 1 was investigated according to the treatment time. For this, $50 \mathrm{~mL}$ of a $200 \mathrm{mg} / \mathrm{L}$ solution was prepared. This concentration required a minimum of $4 \mathrm{~g} / \mathrm{L}$ of MIONPs to start the catalytic oxidation. At the end of the process, MNIONPs were removed from the solution using a magnet. After the first degradation cycle, the solid was dried at $90{ }^{\circ} \mathrm{C}$ and immediately reused for the second cycle of degradation under the same conditions.

\subsection{UV-Vis Spectroscopic Analysis}

The concentration of AR 1 was measured at $505.06 \mathrm{~nm}$ by UV-vis spectrophotometry, using an Ocean View UV-Vis spectrophotometer. Besides, the concentration of $\mathrm{H}_{2} \mathrm{O}_{2}$ during the degradation process was quantified using titanium sulfate spectrophotometry [15]. The absorbance of this solution was measured at $400.13 \mathrm{~nm}$. Previously, a calibration plot based on Beer-law Lambert's equation was established by relating the absorption to AR 1 and the hydrogen peroxide concentration. AR 1 dye degradation efficiency (\%) was calculated using equation 1 , where $\mathrm{Ci}$ is the initial concentration, and $\mathrm{Cf}$ is the final concentration of solution after degradation:

$$
\text { Degradation }(\%)=\frac{(\mathrm{Ci}-\mathrm{Cf})}{\mathrm{Ci}} \cdot 100
$$

\section{Results and Discussion}

\subsection{Characterization of MIONPS}

The morphology and size of the synthesized MIONPs were analyzed by TEM/STEM images (Figure 1). Figure 1a,b shows TEM images of nanoparticles with a quasi-spherical morphology and a size of about $3 \mathrm{~nm}$. MIONPs can aggregate and form large particles due to their strong anisotropy dipolar [16], so certain needle forms are observed in Figure 1c. Using the Digital Micrograph (DM) software 3.7 Gatan, Pleasanton, CA, USA, one large aggregate (Figure 1d) was analyzed and digitally processed to obtain fast Fourier transform (FFT). The bright circular rings indicate the polycrystalline phase in the selected area electron diffraction (SAED) patterns. The spaced-resolved lattice fringes with an interplanar distance of $0.25 \mathrm{~nm}$ agree well with the lattice spacing of $\mathrm{Fe}_{3} \mathrm{O}_{4}$ (311) planes [11]. Figure 1e,f shows the STEM analysis of NPs; these images revealed a better quasi-spherical morphology. The size of NPs in Figure 1d was analyzed to perform a histogram employing the DM software, which confirms an average size of $3.2 \mathrm{~nm}$. 


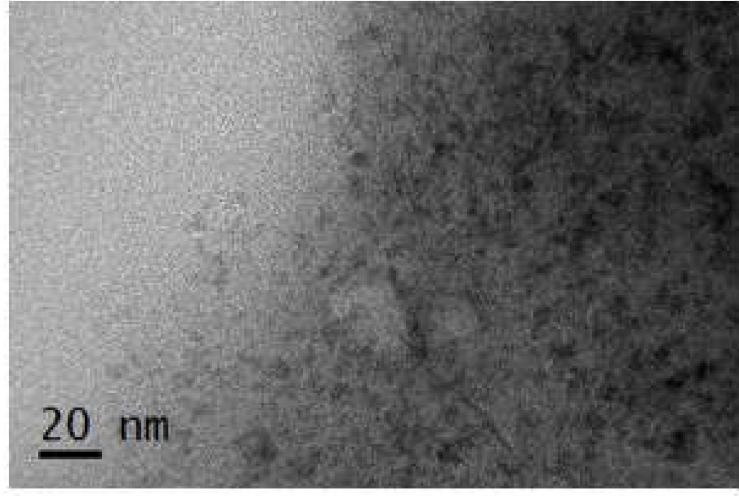

(a)

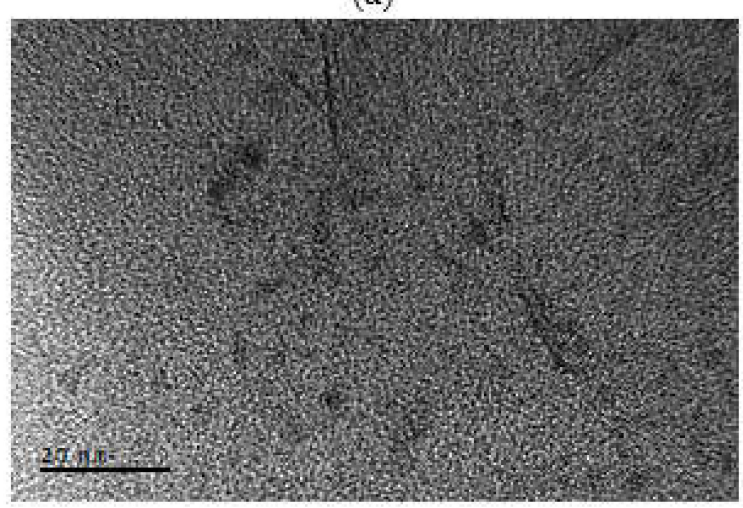

(c)

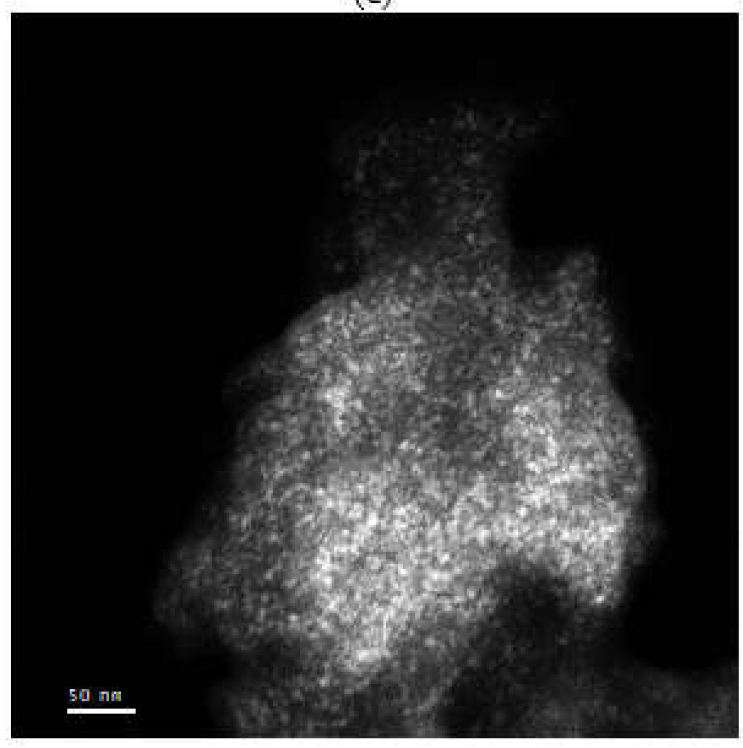

(e)

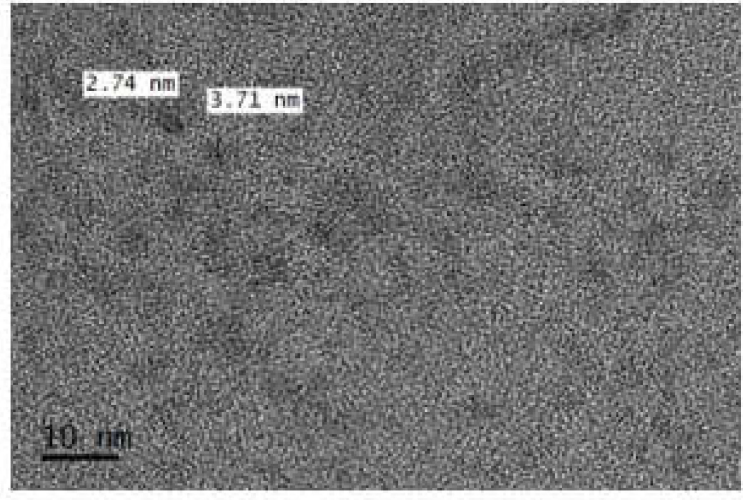

(b)

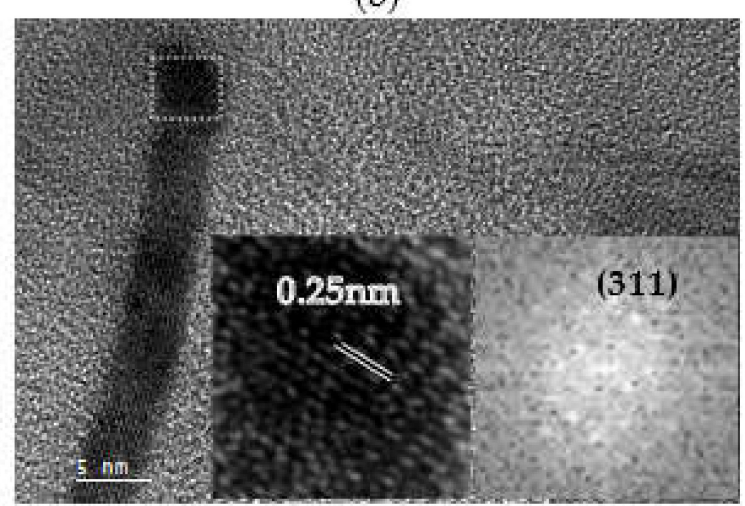

(d)

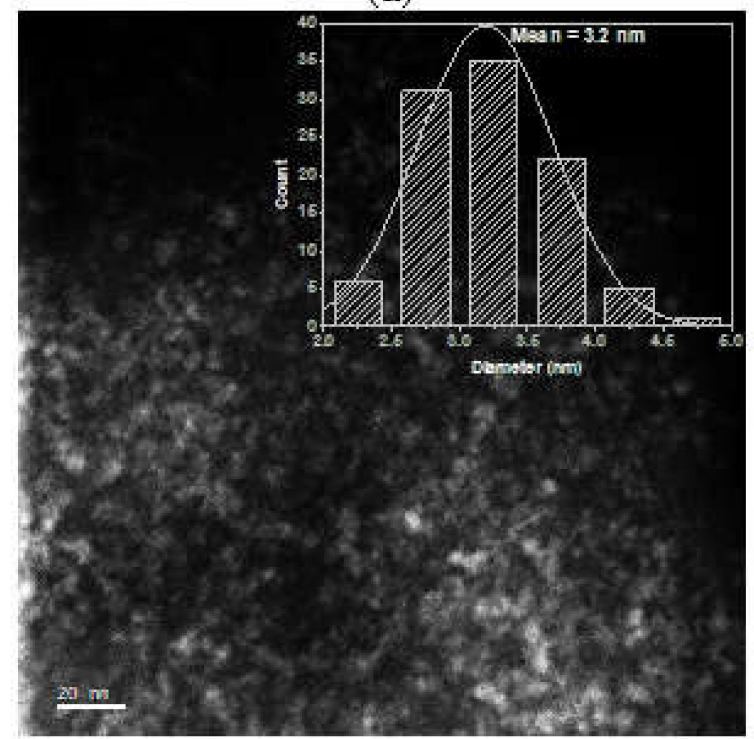

(f)

Figure 1. (a-d) TEM images and (e-f) STEM images of synthesized MIONPs.

The SEM image is seen in Figure 2a with its point EDS analysis applied in the box marked. The EDS spectrum recorded for the nanoparticles is shown in Figure $2 b$, where a strong signal for elemental iron is observed at $6.2 \mathrm{keV}$ and another small signal at $7.1 \mathrm{keV}$. The presence of an oxygen peak at $0.6 \mathrm{keV}$ indicates that iron oxides were formed. The mass relationship corresponds to $\mathrm{Fe}_{3} \mathrm{O}_{4}$. Similar results were obtained using Ridge gourd peel extract [17] to synthesize magnetite nanoparticles. 


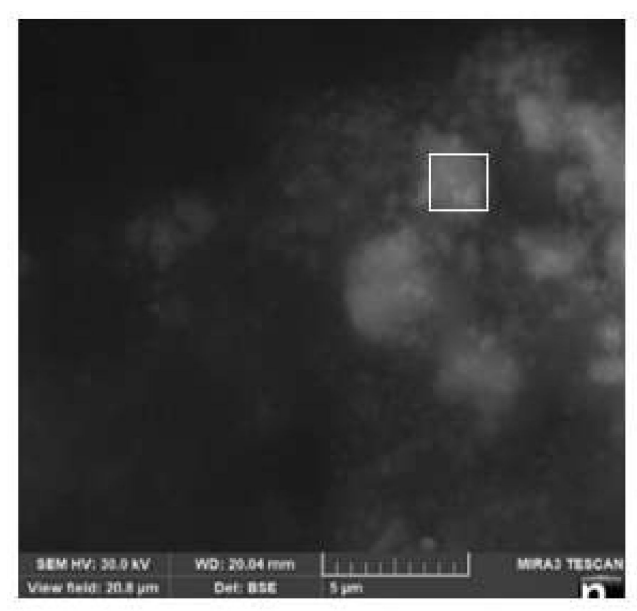

(a)

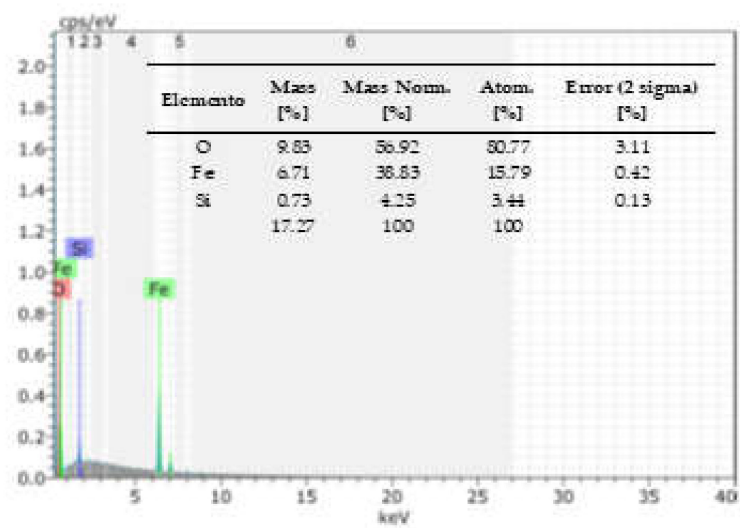

(b)

Figure 2. (a) SEM image and (b) EDS spectrum of MIONPs.

Figure 3a shows the XRD spectrum of synthesized MIONPs. The broad diffraction peaks confirm the formation of an amorphous solid. Here, the width in the middle of the maximum is related to the smallest particle size [18]. The diffractogram depicts the initial crystallizing phase, which corresponds primarily to the magnetite phase [19]. The diffraction patterns are according to the inverse spinel structure of magnetite shown in down of figure. The diffraction pattern card from magnetite powder (19-0629) was obtained from Columbian Carbon Co., in New York, USA. The five characteristic peaks at $2=30.50,35.87,43.65,57.54$, and $63.28^{\circ}$ are assigned to (220), (311), (400), (511), and (440) crystalline planes, respectively. However, it is well established that maghemite $\left(\gamma-\mathrm{Fe}_{2} \mathrm{O}_{3}\right)$ and magnetite $\left(\mathrm{Fe}_{3} \mathrm{O}_{4}\right)$ reveal similar XRD profiles [20]. Bibi et al. [21] published a diffractogram of $\gamma-\mathrm{Fe}_{2} \mathrm{O}_{3} \mathrm{Nps}$ as well as its absorbance spectrum, which showed a peak at $371.71 \mathrm{~nm}$. Compared to this study, MIONPs revealed a different diffractogram in their intensities. Figure $2 \mathrm{~b}$ depicts the absorbance spectrum showing a peak at $228 \mathrm{~nm}$, consistent with previous reports for the magnetite phase [22].

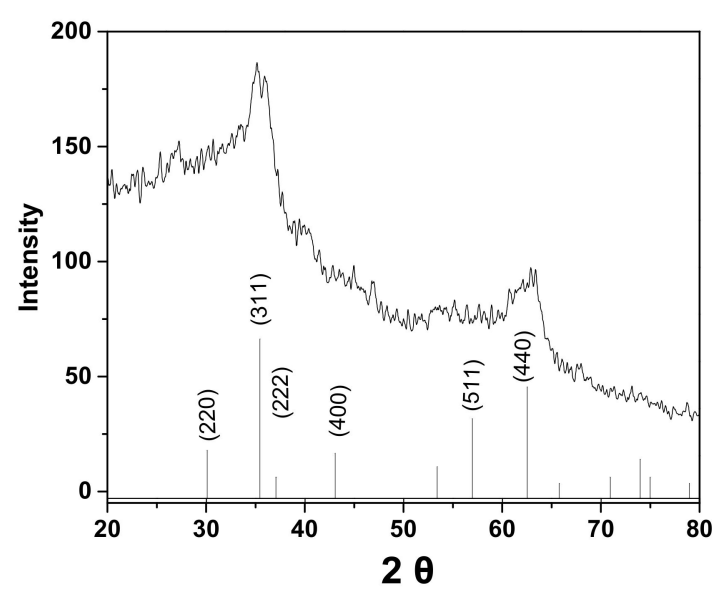

(a)

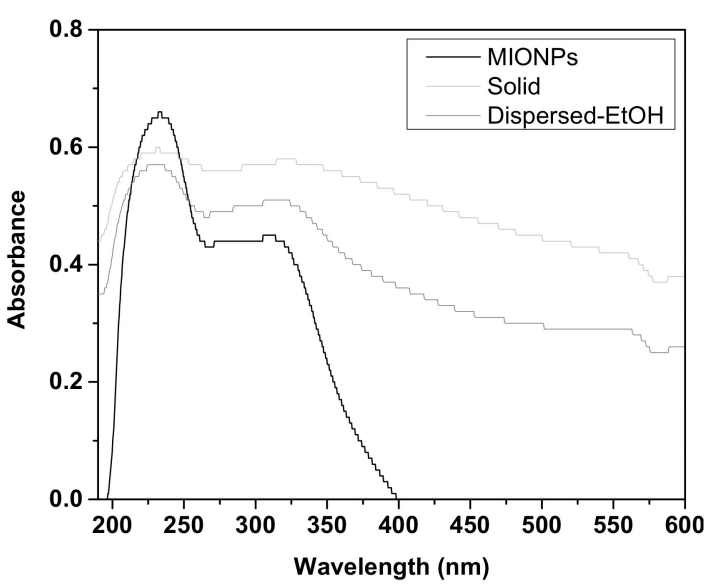

(b)

Figure 3. Spectra of MIONPs: (a) XRD and (b) UV-visible.

UV-visible spectroscopy was performed to analyze the stability of magnetite nanoparticles. Figure $3 b$ depicts the absorbance spectrum of MIONPs in a solid-state after two days of conservation in a closed container without an inert atmosphere. The peak at $228 \mathrm{~nm}$ decreases, while a broad peak of 350-600 increases, indicating a change to the magnetite phase. However, the same figure also shows the spectrum of MIONPs conserved in an 
anhydrous ethanol dispersion after fifteen days. The peak at $228 \mathrm{~nm}$ is still visible, but the broad peak at $350-600 \mathrm{~nm}$ appears. The peak at about $350 \mathrm{~nm}$ is assigned to octahedral $\mathrm{Fe}^{3+}$ in small oligomeric $\mathrm{FeO}_{\mathrm{x}}$ clusters, and the bands at $450-600 \mathrm{~nm}$ are characteristic of the $\mathrm{Fe}_{2} \mathrm{O}_{3}$ aggregates [23]. These results indicate that MIONPs can be stable in the dispersion of anhydrous ethanol during a particular time.

ATR-FTIR analysis was performed to observe the surface purity of the MIONPs, see Figure 4a. According to the literature, the magnetite FTIR spectrum has two strong absorption bands at 570 and $390 \mathrm{~cm}^{-1}$, which can be attributed to the Fe-O stretching mode of the tetrahedral and octahedral sites, respectively [24]. In this study, the Fe-O vibration signal of MIONPs was observed at 540 and $494 \mathrm{~cm}^{-1}$. This shift can be attributed to the small size of the nanoparticles [25]. However, a weak shoulder was observed at $594 \mathrm{~cm}^{-1}$, which could be due to the beginning of the $\gamma-\mathrm{Fe}_{2} \mathrm{O}_{3}$ formation, with absorption bands at 630,590 , and $430 \mathrm{~cm}^{-1}$ [24]. Nevertheless, none of the vibration band was observed around $3400 \mathrm{~cm}^{-1}$, indicating the vibration stretching of the $\mathrm{O}-\mathrm{H}$ group from tannic acid. So, the MIONPs used for the degradation test was free of organic matter.

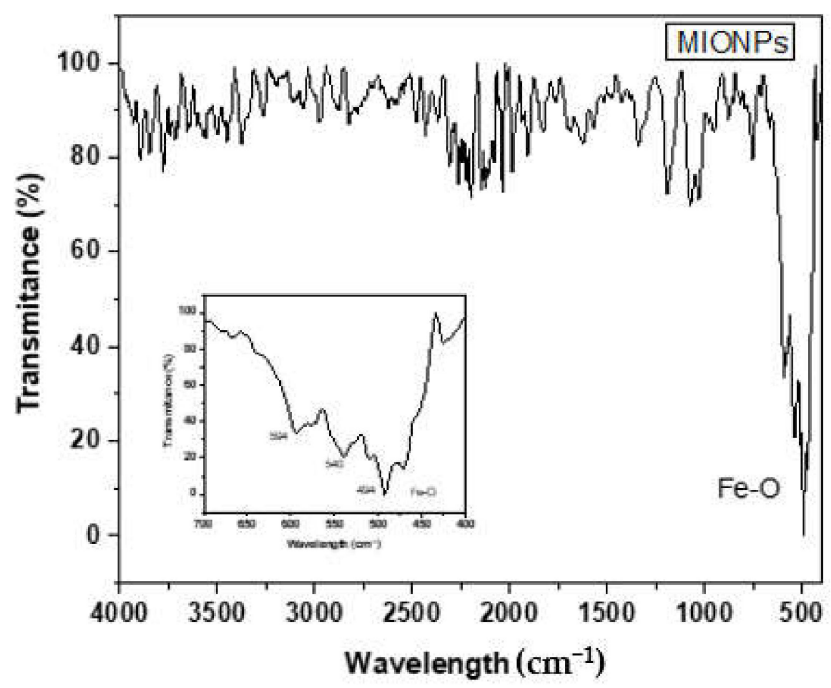

(a)

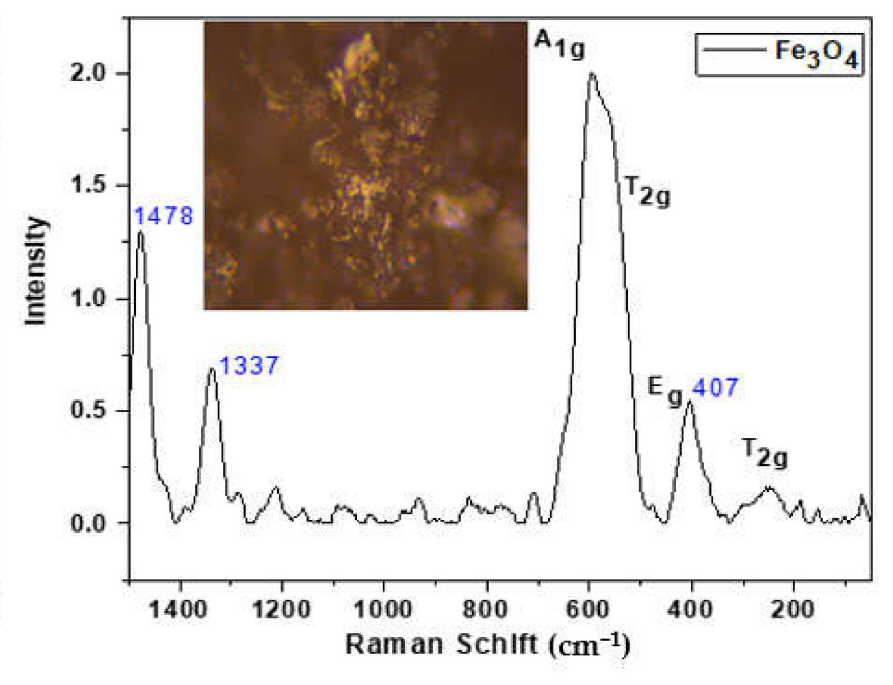

(b)

Figure 4. (a) FTIR and (b) Raman spectra with optical imagen at 50× magnification, of MIONPs.

On the other hand, in Raman spectroscopy, magnetite has a spinel structure, and five phonon bands have been theoretically predicted: one from $\mathrm{A}_{1 \mathrm{~g}}$, a second from $\mathrm{E}_{\mathrm{g}}$, and three from $\mathrm{T}_{2 \mathrm{~g}}$ [26]. Zhang et al. reported the $\mathrm{Fe}_{3} \mathrm{O}_{4}$ nanoparticles Raman spectrum. The $\mathrm{T}_{2 \mathrm{~g}}$ modes were observed at 305 and another at $534 \mathrm{~cm}^{-1}$, the $\mathrm{E}_{\mathrm{g}}$ mode at $513 \mathrm{~cm}^{-1}$, and the $A_{1 g}$ mode at $660 \mathrm{~cm}^{-1}$ [20]. The Raman spectrum of synthesized MIONPs is shown in Figure $3 \mathrm{~b}$. The band assigned to the $\mathrm{A}_{1 \mathrm{~g}}$ mode was shifted to $602 \mathrm{~cm}^{-1}$ due to particle size. However, Profile Breit Wigner Fano (BWF) [18] can better describe this shift to low frequency. Nevertheless, the phonon mode $\left(\mathrm{A}_{1 \mathrm{~g}}\right)$ of $\gamma-\mathrm{Fe}_{2} \mathrm{O}_{3}$ was not observed at $710 \mathrm{~cm}^{-1}$, implying no phases coexist on the surface of MIONPs [19]. On the other hand, the peaks at 407,1337 , and $1478 \mathrm{~cm}^{-1}$ indicate the start of the oxidation to hematite by laser action. This fact is due to the increased temperature of laser-heated spots results in a softening of phonon frequency [27].

MIONPs were successfully synthesized by the coprecipitation method using tannic acid at $\mathrm{pH}<8$. Synthesis of magnetite nanoparticles at $\mathrm{pH}=8$ has been reported using a capping agent synthesized from gallic acid [28]. However, the formation $\gamma-\mathrm{Fe}_{2} \mathrm{O}_{3}$ from the synthesis with tannic acid has also been described at $\mathrm{pH}=12$ [29]. Then, the $\mathrm{pH}$ control in the magnetite synthesis plays an essential role in controlling the oxidation of $\mathrm{Fe}^{2+}$ to $\mathrm{Fe}^{3+}$ [30]. 


\subsection{Degradation Catalyzed by MIONPS}

Figure 5 a shows the absorbance value of the AR 1 solutions treated at different $\mathrm{pH}$ and their corresponding percent degradation in heterogeneous Fenton-like catalysis. The most representative value was the absorbance of 0.01 for the solution at $\mathrm{pH}=3.5$ with $99.12 \%$ of degradation efficiency. These findings are consistent with the Fenton reaction, which shows that the highest degradation efficiency occurs at $\mathrm{pH}=\sim 4$. The degradation efficiency at $\mathrm{pH}>4$ is around $85 \%$, except at $\mathrm{pH}=6.5$, which is $92 \%$. The oxidation process produces inactive ferric oxyhydroxides at $\mathrm{pH}>4$, which reduces degradation efficiency. However, a different behavior was observed when the $\mathrm{pH}=6.5$. Here, the inherent $\mathrm{pH}$ of the solution prevented the beginning formation of oxyhydroxides. Furthermore, the adsorption of the dye on $\mathrm{Fe}^{3+}$ probably occurs through a ligand with the non-protonated carbonyl groups of AR 1. The geometry of the molecule adsorbed on MIONPs surface through a complex plays an essential role in the activation of reactive species, like it has been reported for EDTA complex, which generates hydroxyl and oxygen radicals [31].

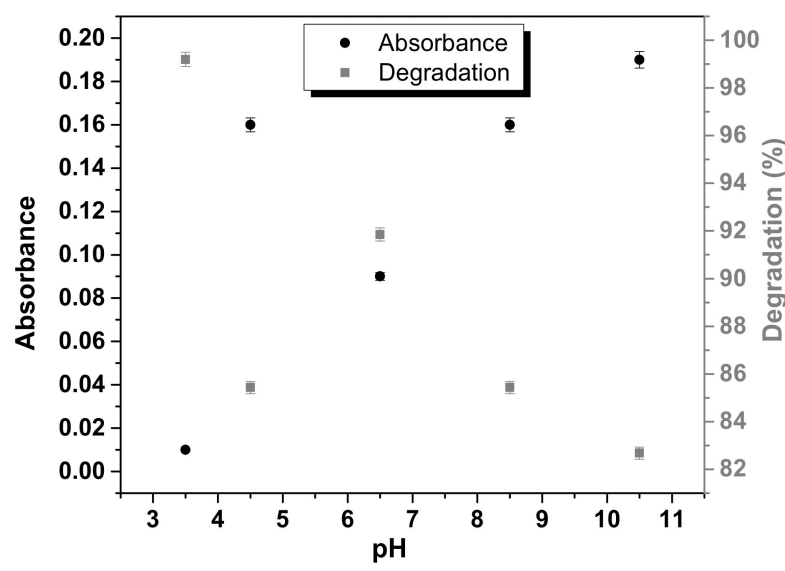

(a)

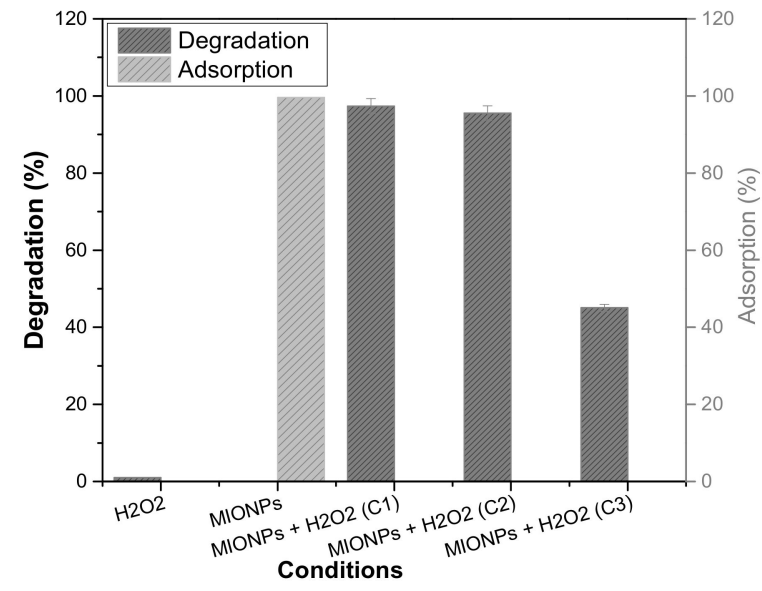

(b)

Figure 5. Graphic of (a) absorbance and degradation (\%) at different $\mathrm{pH}$ and (b) degradation and adsorption at different conditions of the reaction.

Figure $5 \mathrm{~b}$ shows the degradation percentage of AR 1 in an aqueous solution at $200 \mathrm{mg} / \mathrm{L}$ under different conditions after $60 \mathrm{~min}$ of treatment. The adsorption of AR 1 by MIONPs was $99.5 \%$ after 10 min of their addition. The addition of only $\mathrm{H}_{2} \mathrm{O}_{2}$ did not achieve the AR 1 degradation. The dilution of the solution by adding $\mathrm{H}_{2} \mathrm{O}_{2}$ caused just an instantaneous decrease in the AR 1 concentration. However, the oxidation process immediately occurred when $\mathrm{H}_{2} \mathrm{O}_{2}$ was introduced into the system to initiate the catalytic reaction following AR 1 adsorption on MIONPs. The degradation of AR 1 reached 97.4\%. MIONPs stability and reusability were studied because of the essential use for their application. In the second degradation cycle (C2), the efficiency decreased to $96 \%$ and $45 \%$ in the third cycle (C3). Figure 6 shows the Raman spectrum of MIONPs before and after of AR 1 degradation process. The spectrum after degradation corresponds mainly to the magnetite phase, but the maghemite phase begins to be observed at $770 \mathrm{~cm}^{-1}$. In the optical images of MIONPs, a change in porosity, shape, and aggregation state was detected after the treatment process, which corroborates that the MIONPs act as adsorbents and exhibit catalytic activity for decomposition $\mathrm{H}_{2} \mathrm{O}_{2}$. 


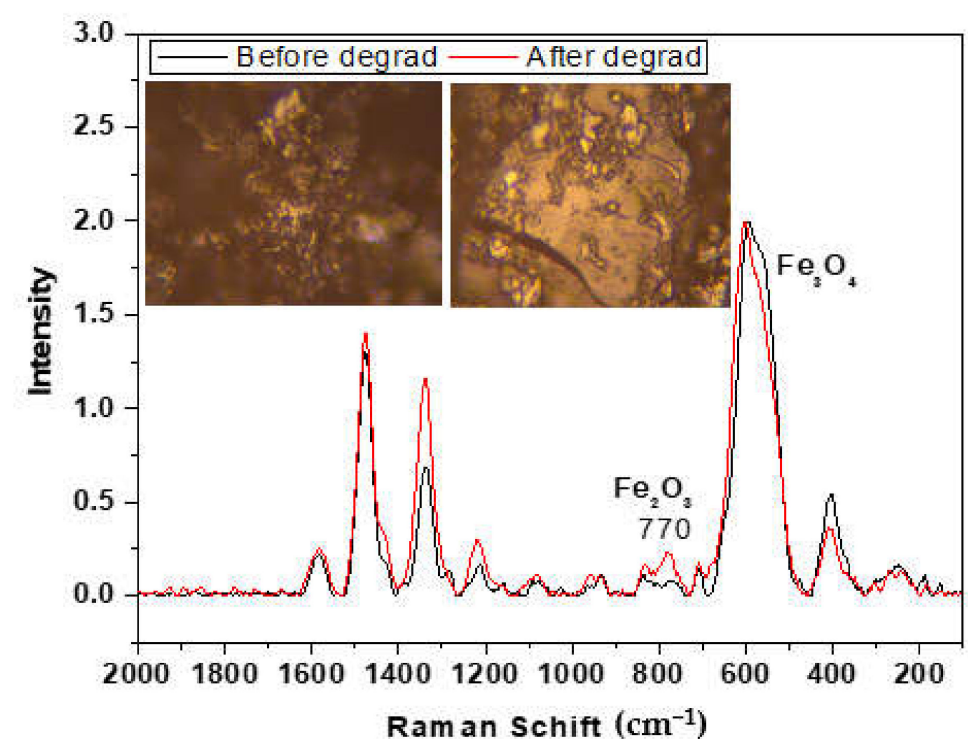

Figure 6. Raman spectra of MIONPs before and after AR 1 degradation.

\subsection{Peroxidase-like Activity of MIONPS}

The degradation of AR 1 as a function of time is shown in Figure $7 \mathrm{a}$ for a concentration of $200 \mathrm{mg} / \mathrm{L}$. This concentration is mainly reported for effluents that need to be treated [1]. The double peak with a maximum at $\lambda=531$ and $505.5 \mathrm{~nm}$ is the characteristic band of the conjugated electron structure (chromophore group) corresponding to the $\pi-\pi^{*}$ transition bond of $\mathrm{N}=\mathrm{N}$, while the second peak at about $325 \mathrm{~nm}$ corresponding to the $\pi-\pi^{*}$ bond of $\mathrm{N}-\mathrm{H}$. The $240 \mathrm{~nm}$ and $280 \mathrm{~nm}$ are the bands due to benzene and naphthalene rings [32]. The solution's absorbance was measured at $505 \mathrm{~nm}$. Figure 7a depicts the discoloration image of solutions treated each $10 \mathrm{~min}$, with their absorbance spectra. The graph shows that the double absorption peak at $505 \mathrm{~nm}$ and $531 \mathrm{~nm}$ decreases with increasing time, indicating that AR 1 degradation is effective. The intensity of this band significantly reduced after the addition of $\mathrm{H}_{2} \mathrm{O}_{2}$ (initial). The highest percentage of degradation (84\%) occurs within the first $10 \mathrm{~min}$, and degradation was $97.4 \%$ completed up to $40 \mathrm{~min}$. UV-visible spectra indicate the AR 1 degradation to small molecules from the chromophore groups.

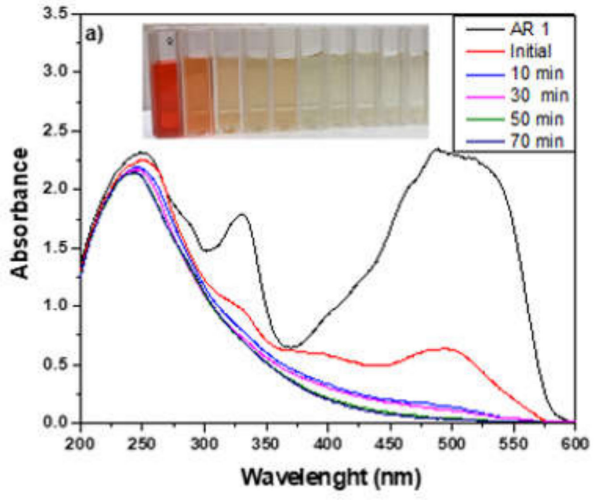

(a)

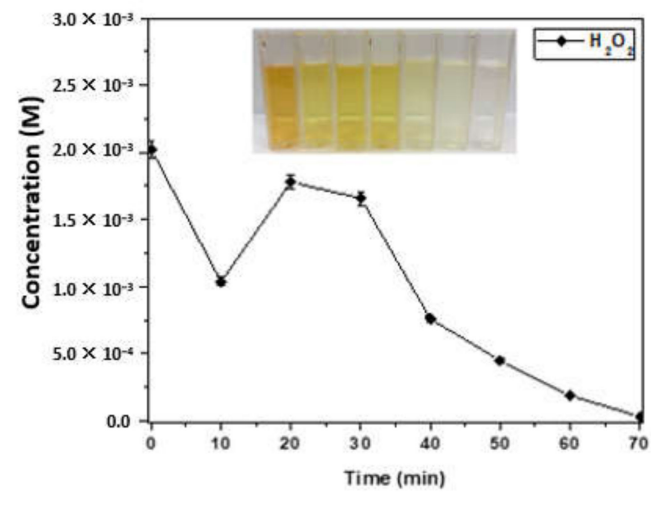

(b)

Figure 7. (a) UV-Visible spectra of AR 1 and (b) concentration of $\mathrm{H}_{2} \mathrm{O}_{2}$ in the degradation process.

Figure $7 \mathrm{~b}$ shows the concentration of $\mathrm{H}_{2} \mathrm{O}_{2}$ quantified during the heterogeneous Fenton-like catalysis depicted in Figure 7a. The titanium sulfate spectrophotometry method was used to determine the concentration of peroxide. It was observed that the $\mathrm{H}_{2} \mathrm{O}_{2}$ decreased in the first ten minutes, which corresponded to the highest degradation seen in the first minutes after initiation with hydrogen peroxide. After, $\mathrm{H}_{2} \mathrm{O}_{2}$ generation catalyzed 
by MIONPs is followed in the next $10 \mathrm{~min}$ to achieve the maximum dye degradation. Finally, the peroxide consumption is observed slowly and concludes in $50 \mathrm{~min}$ more.

\subsection{Mechanism of AR 1 Degradation}

Peroxidases are a group of enzymes capable of catalyzing the oxidation of hydrogen peroxide into hydroxyl radicals. These radicals further participate in electron exchange with substrates producing color on oxidation. This activity is performed by the HEMO group (a Fe ion coordinated with a porphyrin that acts as a tetradentate ligand), which is found in peroxidase-type enzymes. Gao et al. [33] reported on the peroxidase-like activity of magnetite nanoparticles in the presence of peroxide. However, it has been stated that $\mathrm{Fe}_{3} \mathrm{O}_{4}$ MNPs are not as effective in the treatment of hazardous organic pollutants. It is necessary to increase the $\mathrm{H}_{2} \mathrm{O}_{2}$ activation capacity of $\mathrm{Fe}_{3} \mathrm{O}_{4} \mathrm{MNPs}$, with the assistance of ultrasonic irradiation [13]. In this study, we investigate the peroxidase-like activity of MIONPs in the oxidation of a recalcitrant dye in the absence of assisted irradiation. The reaction mechanism of MIONPs in the generation of $\mathrm{OH}$ radicals is due to their actuation as redox enzymes by the electron exchange escalated by their superficial atoms. Besides, when the organic molecule (AR 1) is adsorbed on the surface of MIONPs through electronic interaction at the molecule-metal interface to form a monolayer, these electrostatic and steric interactions promote the catalytic activity on its degradation. Then, the redox reaction occurs on the surface of MIONPs, but is related to the heterogeneous Fenton reaction in solution through the following equations [31]:

$$
\begin{gathered}
\mathrm{Fe}^{2+}+\mathrm{H}_{2} \mathrm{O}_{2} \longrightarrow \mathrm{Fe}^{3+}+{ }^{\bullet} \mathrm{OH}+\mathrm{OH}^{-} \\
\mathrm{Fe}^{3+}+\mathrm{H}_{2} \mathrm{O}_{2} \longrightarrow \mathrm{Fe}^{2+}+\cdot \mathrm{OOH}+\mathrm{H}^{+} \\
\mathrm{HO}_{2}{ }^{\cdot}+\mathrm{HO}_{2}{ }^{\bullet} \longrightarrow \mathrm{H}_{2} \mathrm{O}_{2}+\mathrm{O}_{2} \\
\cdot \mathrm{OH}+\mathrm{AR} 1 \leftrightarrow \quad \text { intermediates } \leftrightarrow \mathrm{CO}_{2}+\mathrm{H}_{2} \mathrm{O}
\end{gathered}
$$

AR 1 oxidation begins when the bare minimum of $\mathrm{H}_{2} \mathrm{O}_{2}$ is added to the dye solution to begin the catalytic activity of MIONPs. This relationship is not stoichiometric, unlike the conventional Fenton reaction. Then, the degradation of AR 1 occurs mainly at the solid-liquid interfaces of MIONPs, where the formation of hydroxyl radicals is due to the catalyzed decomposition of hydrogen peroxide by the active sites $\left(\mathrm{Fe}^{2+}\right.$ and $\left.\mathrm{Fe}^{3+}\right)$ of MIONPs.

Figure 8a shows the Raman spectrum of AR 1 (down), where a broad and strong peak was observed at $1580 \mathrm{~cm}^{-1}$ corresponding to the vibrational signal $\mathrm{C}=\mathrm{C}$ of the aromatic rings. The carbonyl signal of the amide group coexists in this peak because the electric field from the aromatic ring causes a shift at a low frequency. The azo group $\mathrm{N}=\mathrm{N}$ signal was detected at $1353 \mathrm{~cm}^{-1}$, and the aromatic ring C-N bond vibration signal was detected at $1330 \mathrm{~cm}^{-1}$. The sulfate group $\mathrm{S}=\mathrm{O}$ and the vibration signal from the aromatic ring C-S bond were observed at $1156 \mathrm{~cm}^{-1}$ and $656 \mathrm{~cm}^{-1}$. The AR 1 spectrum (up) adsorbed on the surface of MIONPs showed the signal of $\mathrm{C}=\mathrm{O}$ from the amide group displaced at $1748 \mathrm{~cm}^{-1}$ because of electrostatic interaction with MIONPs. The vibrational signal from the aromatic ring occurs at $\mathrm{C}=\mathrm{C}$ at $1580 \mathrm{~cm}^{-1}$, but another peak corresponding to this signal appears at $880 \mathrm{~cm}^{-1}$. This unusual signal is caused by a change in the symmetry of the molecule that interacts with the MIONPs surface. Finally, two vibrational signals appear that correspond to the $\mathrm{C}-\mathrm{O}$ and $\mathrm{N}-\mathrm{O}$ bonds, most likely as a result of AR 1 forming a coordination ligand with $\mathrm{Fe}^{2+}$ through the amide and azo groups. The strong signals at 253 and $375 \mathrm{~cm}^{-1}$ correspond to $\gamma$-FeOOH [26]. 


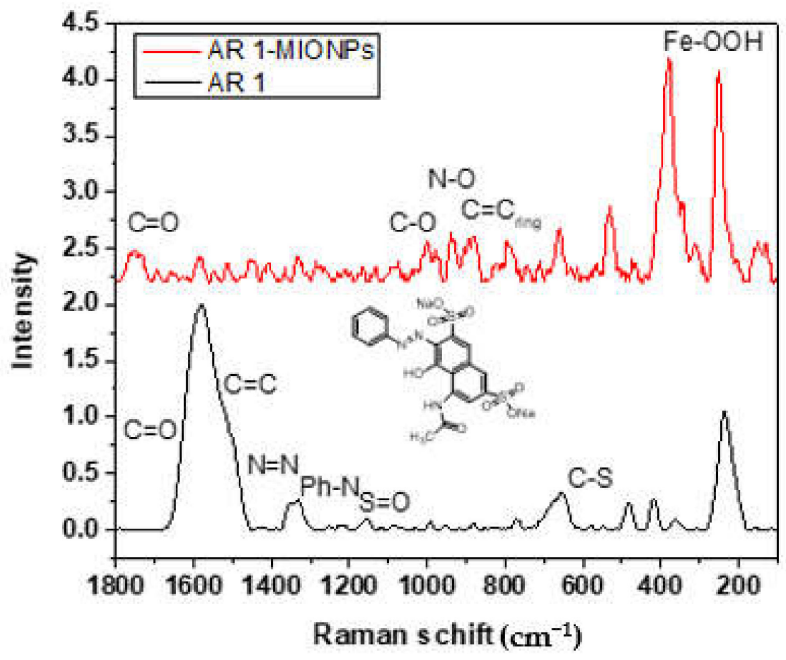

(a)

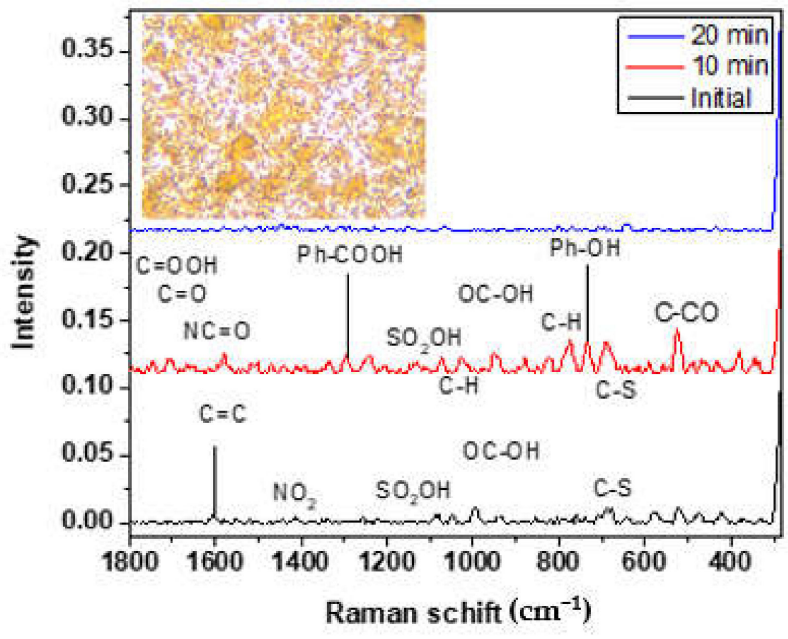

(b)

Figure 8. Raman spectra of (a) AR 1 (down) and AR 1 adsorbed on MIONPs (up); (b) intermediaries' compounds, and optical image at $50 \times$ magnification of the SERS substrate (initial).

\subsection{Compounds Detected by SERS in AR 1 Degradation}

SERS analysis was performed on solutions obtained from Figure 7a. To detect AR 1, the initial and treated solutions were deposited on Ag nanoflowers [34] (on Si wafer substrate). Figure $8 \mathrm{~b}$ shows the spectra of the initial, at $10 \mathrm{~min}$, and $20 \mathrm{~min}$ solutions from the degradation process. After this time, no signal was detected for the following solutions. The spectra present the signals corresponding to different functional groups linked to intermediaries' compounds reported and detected by mass spectroscopy during the $\mathrm{H}_{2} \mathrm{O}_{2}$-photolysis degradation of AR 1 [32].

Figure 9 shows the AR 1 degradation mechanism through oxidation by radicals ${ }^{\bullet} \mathrm{OH}$. In the initial spectrum (immediate analysis after adding peroxide), the signal from azo group $\mathrm{N}=\mathrm{N}$ at $1353 \mathrm{~cm}^{-1}$ in compound 1 was not observed. Instead, the vibrational signal for the $\mathrm{NO}_{2}$ group was detected at $1412 \mathrm{~cm}^{-1}$ because of $\mathrm{N}=\mathrm{N}$ bond cleavage to obtain compound 2 and nitrophenol $\left(\mathrm{C}_{6} \mathrm{H}_{5} \mathrm{NO}_{2}\right)$. Besides, the signal of the $\mathrm{SO}_{2} \mathrm{OH}$ group in intermediaries' compounds was detected at $1084 \mathrm{~cm}^{-1}$. The spectrum corresponding to ten minutes of treatment revealed more signals with higher intensities from the functional groups in compounds $4,5,6$, and 7 . The signal corresponding to the $\mathrm{C}=\mathrm{O}$ from carboxylic acid in compounds 5, 6, and 7 was detected at $1747 \mathrm{~cm}^{-1}$; the vibrational stretching of the $\mathrm{C}=\mathrm{O}$ bond in compound 4 was observed at $1706 \mathrm{~cm}^{-1}$, and the signal of $\mathrm{C}=\mathrm{O}$ from the amide group in compounds 3,4 , and 6 was seen at $1660 \mathrm{~cm}^{-1}$. At $1580 \mathrm{~cm}^{-1}$, the vibrational signal was observed at $C=C$ from the aromatic rings. At $1291 \mathrm{~cm}^{-1}$ and $731 \mathrm{~cm}^{-1}$, the benzoic acid and phenol peaks were detected, respectively. Then, the main intermediaries' compounds in the degradation of AR 1 can be observed after ten minutes of catalytic activity of MIONPs. However, signals in the spectrum of the solution after $20 \mathrm{~min}$ of treatment decrease considerably. 


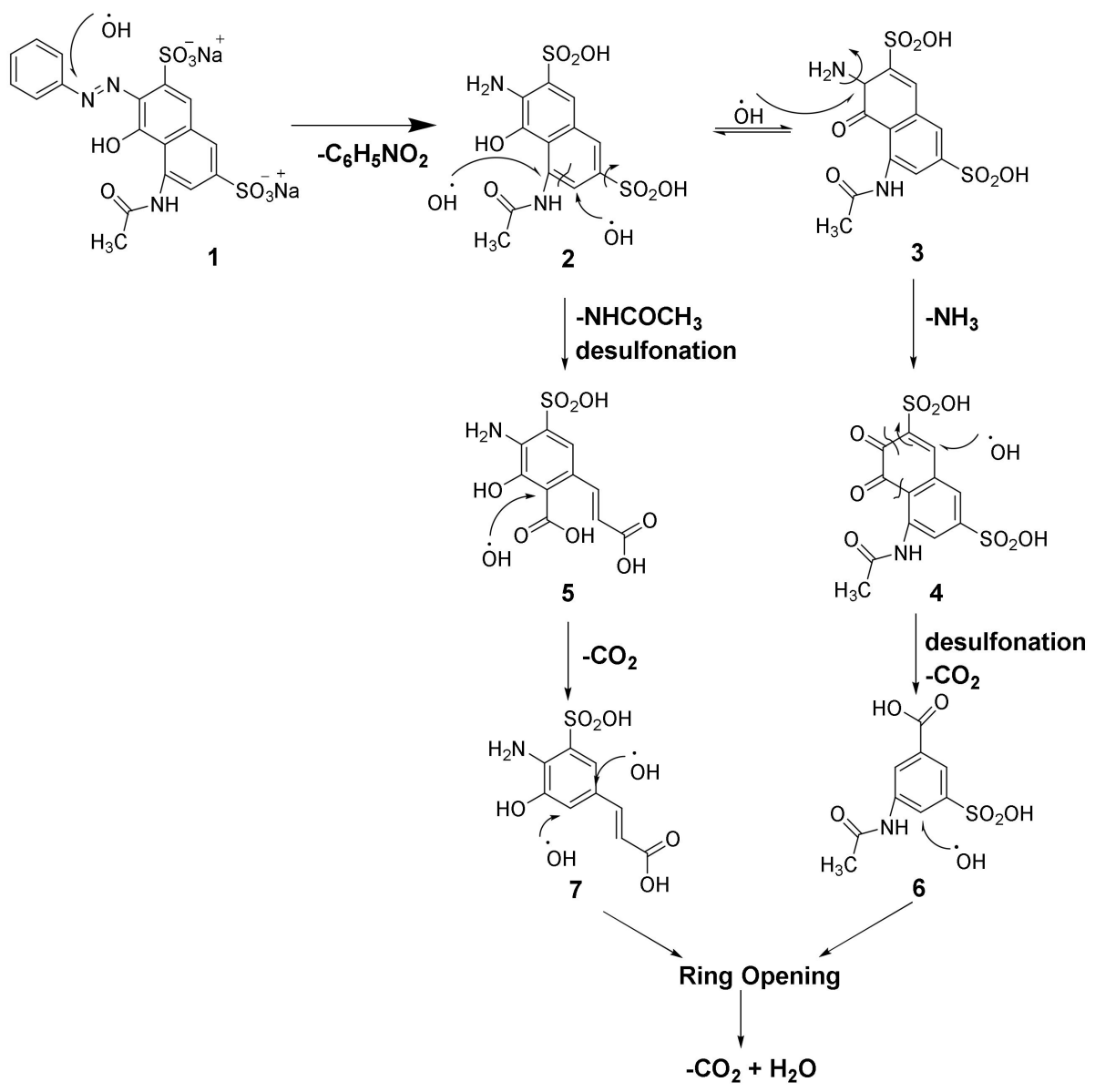

Figure 9. AR 1 degradation mechanism through oxidation by radicals $\bullet^{\bullet} \mathrm{OH}$.

The results obtained demonstrate that the application of MIONPs in AR 1 degradation suggests the superiority of the conventional Fenton-like catalysts through a dye highly recalcitrant. In this context, several studies on the degradation of azo-type organic dyes using iron oxide nanoparticles in heterogeneous Fenton-like catalysis reactions have been published. Table 1 depicts a comparison of those studies and this work. The peroxidaselike activity of MIONPs was reported for the degradation of Rhodamine (RhB) using ultrasonic irradiation (UI) [13,35]. The efficiency of degradation (90\%) is due to the synergy of the ultrasonic and Fenton processes. However, this technology has the disadvantage of ultrasonic systems of high power consumption. Alternatively, magnetite nanoparticles supported on graphene oxide (GO) presented a good efficiency in degrading Acid orange 7 (AO 7) in normal conditions without irradiation. The Magnetite NPs without support of GO showed the same efficiency after $45 \mathrm{~min}$ of the process achieving $80 \%$, and those supported in GO reached $98 \%$ of AO 7 degradation after three hours [11]. Nanocomposites of stable hematite nanoparticles with $\mathrm{SiO}_{2}$ have also been reported for heterogeneous Fenton-like catalysis. The degradation efficiency was excellent, but the treatment times were too long $[23,36]$. Compared to the other reported results, the synthesized MIONPs in this work present an excellent peroxidase-like activity in degrading a recalcitrant contaminant at a high concentration. The high efficiency of degradation under normal temperature conditions without irradiation is one of the study's advantages. Besides, the particle size $(3.2 \mathrm{~nm})$ of MIONPs and the adsorption of AR 1 via-interactions from the aromatic ring structure on its basal plane and NPs surface contribute to the efficiency of this work. This dye adsorption increases the local concentration of AR 1 within the vicinity of the active sites to be further oxidized by the generated hydroxyl radicals. 
Table 1. Degradation studies of azo dyes using different nanomaterials and process conditions.

\begin{tabular}{|c|c|c|c|c|}
\hline $\begin{array}{l}\text { Organic Dyes } \\
\text { [Concentration] }\end{array}$ & Catalyst & Conditions & $\begin{array}{l}\text { Degradation } \\
\text { and Time }\end{array}$ & Reference \\
\hline $\begin{array}{c}\mathrm{RhB} \\
(10 \mathrm{mg} / \mathrm{L})\end{array}$ & $\begin{array}{l}\mathrm{Fe}_{3} \mathrm{O}_{4} \mathrm{NPs} \\
(10-15 \mathrm{~nm})\end{array}$ & $\begin{array}{c}\text { Cat }=0.5 \mathrm{~g} / \mathrm{L}, \mathrm{H}_{2} \mathrm{O}_{2} 40 \mathrm{mM} \\
\mathrm{pH}=5, \mathrm{~T}=25^{\circ} \mathrm{C}, \mathrm{UI}=20 \mathrm{kHz}\end{array}$ & $\begin{array}{l}90 \% \\
1 \mathrm{~h}\end{array}$ & [13] \\
\hline $\begin{array}{l}\mathrm{RhB} \\
(10 \mathrm{mg} / \mathrm{L})\end{array}$ & $\begin{array}{c}\mathrm{Ag}_{3} \mathrm{PO}_{4}-\mathrm{Fe}_{3} \mathrm{O}_{4} @ \mathrm{AB} \\
(10 \mathrm{~nm})\end{array}$ & $\begin{array}{c}\text { Cat }=0.1 \mathrm{~g} / \mathrm{L}, \mathrm{H}_{2} \mathrm{O}_{2}=1.5 \mathrm{mM} \\
\mathrm{pH}=3.5, \mathrm{~T}=25^{\circ} \mathrm{C}, \mathrm{UI}=40-970 \mathrm{kHz}\end{array}$ & $\begin{array}{l}99.3 \% \\
1 \mathrm{~h}\end{array}$ & [35] \\
\hline $\begin{array}{c}\mathrm{AO} 7 \\
(35 \mathrm{mg} / \mathrm{L})\end{array}$ & $\begin{array}{c}\mathrm{GO}-\mathrm{Fe}_{3} \mathrm{O}_{4} \mathrm{NPs} \\
\mathrm{Fe}_{3} \mathrm{O}_{4} \mathrm{NPs}(10 \mathrm{~nm})\end{array}$ & $\begin{array}{c}\text { Cat }=0.2 \mathrm{~g} / \mathrm{L}, \mathrm{H}_{2} \mathrm{O}_{2}=22 \mathrm{mM} \\
\mathrm{pH}=3, \mathrm{~T}=25^{\circ} \mathrm{C}\end{array}$ & $\begin{array}{l}98 \%, 3 \mathrm{~h} \\
\sim 80 \%\end{array}$ & [11] \\
\hline $\begin{array}{c}\mathrm{MB} \\
(120-300 \mathrm{mg} / \mathrm{L})\end{array}$ & $\alpha-\mathrm{Fe}_{2} \mathrm{O}_{3} / \mathrm{SiO}_{2}$ & $\begin{array}{c}\text { Cat }=1 \mathrm{~g} / \mathrm{L}, \mathrm{H}_{2} \mathrm{O}_{2}=2 \mathrm{M} \\
\mathrm{pH}=3, \mathrm{~T}=25^{\circ} \mathrm{C}\end{array}$ & $\begin{array}{l}99 \% \\
60 \mathrm{~h}\end{array}$ & [23] \\
\hline $\begin{array}{c}\mathrm{MB}(50 \mathrm{mg} / \mathrm{L}) \\
\operatorname{RhB}(25 \mathrm{mg} / \mathrm{L}))\end{array}$ & $\alpha-\mathrm{Fe}_{2} \mathrm{O}_{3} @ \mathrm{Ti}-\mathrm{tmSiO}{ }_{2}$ & $\begin{array}{c}\text { Cat }=0.25 \mathrm{~g} / \mathrm{L}, \mathrm{H}_{2} \mathrm{O}_{2}=53 \mathrm{mM} \\
\mathrm{pH}=4, \mathrm{~T}=50^{\circ} \mathrm{C}\end{array}$ & $\begin{array}{c}100 \%, 5.5 \mathrm{~h} \\
100 \%, 9 \mathrm{~h}\end{array}$ & [36] \\
\hline $\begin{array}{c}\text { AR } 1 \\
(200 \mathrm{mg} / \mathrm{L})\end{array}$ & $\begin{array}{l}\mathrm{Fe}_{3} \mathrm{O}_{4} \mathrm{NPs} \\
(3.2 \mathrm{~nm})\end{array}$ & $\begin{array}{c}\text { Cat }=4 \mathrm{~g} / \mathrm{L}, \mathrm{H}_{2} \mathrm{O}_{2}=2 \mathrm{mM} \\
\mathrm{pH}=3.5, \mathrm{~T}=25^{\circ} \mathrm{C}\end{array}$ & $\begin{array}{l}97.4 \% \\
1 \mathrm{~h}\end{array}$ & This work \\
\hline
\end{tabular}

\section{Conclusions}

Synthesis MIONPs with tannic acid is a good and efficient method in the obtention of magnetite nanoparticles. The nanoparticles were characterized and found to be $3.2 \mathrm{~nm}$ in average size, with a quasi-spherical morphology. The various spectroscopies and microscopies showed their chemical composition and magnetite phase. The peroxidase-like activity of the synthesized nanoparticles was verified by a heterogeneous Fenton-like catalysis reaction involving the degradation of AR 1 . A high concentration of AR 1 was mineralized with an efficiency of $97.4 \%$ in one hour. MIONPs activity is strongly dependent on their size, shape, and surface structure; these characteristics can be appropriately tuned during their synthesis. Furthermore, the SERS technique identified the intermediary compounds in the degradation process. In the future, these nanoparticles could be supported in other nanomaterials to investigate their efficiency in heterogeneous Fenton-like catalysis, which would address the disadvantage of NPs instability and aggregation.

Author Contributions: Conceptualization, H.M. and E.V.-V.; Methodology, E.V.-V.; Formal Analysis, H.M. and E.V.-V.; Investigation, E.V.-V.; Resources, H.M. and F.C.; Data Curation, E.V.-V.; WritingOriginal Draft Preparation, E.V.-V.; Writing-Review \& Editing, H.M. and F.C.; Visualization, H.M. and F.C.; Supervision, H.M.; Project Administration, H.M.; Funding Acquisition, H.M. All authors have read and agreed to the published version of the manuscript.

Funding: This research received no external funding.

Institutional Review Board Statement: Not applicable.

Informed Consent Statement: Not applicable.

Data Availability Statement: Not applicable.

Acknowledgments: The authors thank Guadalupe Zavala from the Institute of Biotechnology, UNAM, and Samuel Tehuacanero-Cuapa from Physic Institute, UNAM; for their microscopy analysis support. To María Luisa Ramon-García from the Renewable Energy Institute, UNAM, for his X-ray diffraction analysis support. To Osvaldo Flores-Cedillo, and Ing. Hector H. Hinojosa-Galvan from ICF, UNAM for their technical support. Finally, to Cecilia A. Reyes-Aranda and Reynel HernándezMartínez from UAEM for their support in the experiments.

Conflicts of Interest: The authors declare no conflict of interest.

\section{References}

1. Singh, K.; Arora, S. Removal of synthetic textile dyes from wastewaters: A critical review on present treatment technologies. Crit. Rev. Environ. Sci. Technol. 2011, 41, 807-878. [CrossRef]

2. Shaul, G.M.; Holdsworth, T.J.; Dempsey, C.R.; Dostal, K.A. Fate of water-soluble azo dyes in the activated sludge process. Chemosphere 1991, 22, 107-119. [CrossRef] 
3. UNESCO. The United Nations World Water Development Report 4: Managing Water Report under Uncertainty and Risk; United Nations Educational, Scientific and Cultural Organization: Paris, France, 2012; Volume 1.

4. Brillas, E.; Martínez-Huitle, C.A. Decontamination of wastewaters containing synthetic organic dyes by electrochemical methods. An up dated review. Appl. Catal. B Environ. 2015, 166, 603-643. [CrossRef]

5. Anjaneyulu, Y.; Sreedhara Chary, N.; Suman Raj, D.S. Decolorization of industrial effluents-available methods and emerging technologies-A review. Rev. Environ. Sci. Biotechnol. 2005, 4, 245-273. [CrossRef]

6. Florenza, X.; Sales Solano, A.M.; Centellas, F.; Martínez-Huitle, C.A.; Brillasa, E.; Garcia-Segura, S. Degradation of the azo dye Acid Red 1 by anodic oxidation and indirectelectrochemical processes based on Fenton's reaction chemistry. Relationship between decolorization, mineralization and products. Electrochim. Acta 2014, 142, 276-288. [CrossRef]

7. Do Vale-Júnior, E.; Da Silva, D.R.; Fajardo, A.S.; Martínez-Huitle, C.A. Treatment of an azo dye effluent by peroxi-coagulation and its comparison to traditional electrochemical advanced processes. Chemosphere 2018, 204, 548-555. [CrossRef]

8. Javaid, R.; Qazi, U.Y. Catalytic Oxidation Process for the Degradation of Synthetic Dyes: An Overview. Int. J. Environ. Res. Public Health 2019, 16, 2066. [CrossRef]

9. Hodges, B.C.; Cates, E.L.; Kim, J.-H. Challenges and prospects of advanced oxidation water treatment processes using catalytic nanomaterials. Nat. Nanotechn. 2018, 13, 642-650. [CrossRef] [PubMed]

10. Munoz, M.; de Pedro, Z.M.; Casas, J.A.; Rodriguez, J.J. Preparation of magnetite-based catalysts and their application in heterogeneous Fenton oxidation-A review. Appl. Catalys. B Environ. 2015, 176, 249-265. [CrossRef]

11. Zubir, N.A.; Yacou, C.; Motuzas, J.; Zhang, X.; Diniz da Costa, J.C. Structural and functional investigation of graphene oxideFe3O4 nanocomposites for the heterogeneous Fenton-like reaction. Sci. Rep. 2014, 4, 4594. [CrossRef]

12. Maharjan, A.; Dikshit, P.K.; Gupta, A.; Kim, B.S. Catalytic activity of magnetic iron oxide nanoparticles for hydrogen peroxide decomposition: Optimization and characterization. J. Chem. Technol. Biotechnol. 2020, 95, 2495-2508. [CrossRef]

13. Wang, N.; Zhu, L.; Wang, M.; Wang, D.; Tang, H. Sono-enhanced degradation of dye pollutants with the use of $\mathrm{H} 2 \mathrm{O} 2$ activated by $\mathrm{Fe} 3 \mathrm{O} 4$ magnetic nanoparticles as peroxidase mimetic. Ultrason. Sonochem. 2010, 17, 78-83. [CrossRef] [PubMed]

14. Robles, H. Tannic Acid. In Encyclopedia of Toxicology, 3rd ed.; Elsevier: Amsterdam, The Netherlands, 2014; pp. 474-475. [CrossRef]

15. Du, X.; Xu, Y.; Qin, L.; Lu, X.; Liu, Q.; Bai, Y. Simple and Rapid Spectrophotometric Determination of Titanium on Etched Aluminum Foils. Am. J. Anal. Chem. 2014, 5, 149-156. [CrossRef]

16. Deng, J.; Wen, X.; Wang, Q. Solvothermal in situ synthesis of Fe3O4-multiwalled carbon nanotubes with enhanced heterogeneous Fenton-like activity. Mater. Res. Bull. 2012, 47, 3369-3376. [CrossRef]

17. Cheera, P.; Karlapudi, S.; Sellola, G.; Ponneri, V. A facile green synthesis of spherical Fe3O4 magnetic nanoparticles and their effect on degradation of methylene blue in aqueous solution. J. Mol. Liq. 2016, 221, 993-998. [CrossRef]

18. Bhattacharjee, S.; Mazumder, N.; Mondal, S.; Panigrahi, K.; Banerjee, A.; Das, D.; Sarkar, S.; Roy, D.; Kumar Chattopadhyay, K. Size-modulation of functionalized Fe3O4: Nanoscopic customization to devise resolute piezoelectric nanocomposites. Dalton Trans. 2020, 49, 7872. [CrossRef]

19. Ali, S.; Khan, S.A.; Yamani, Z.H.; Qamar, M.T.; Morsy, M.A.; Sarfraz, S. Shape and size-controlled superparamagnetic iron oxidenanoparticles using various reducing agents and their relaxometric properties by Xigo acorn area. Appl. Nanosci. 2019, 9, 479-489. [CrossRef]

20. Zhang, X.; Niu, Y.; Meng, X.; Li, Y.; Zhao, J. Structural evolution and characteristics of the phase transformations between $\alpha$-Fe2O3, Fe3O4 and $\gamma$-Fe2O3 nanoparticles under reducing and oxidizing atmospheres. Cryst. Eng. Comm. 2013, 15, 8166-8172. [CrossRef]

21. Bibi, I.; Nazar, N.; Ata, S.; Sultan, M.; Ali, A.; Abbas, A.; Jilani, K.; Kamal, S.; Sarim, F.M.; Khan, M.I.; et al. Green synthesis of iron oxide nanoparticles using pomegranate seeds extract and photocatalytic activity evaluation for the degradation of textile dye. $J$. Mater. Res. Technol. 2019, 8, 6115-6124. [CrossRef]

22. Razack, S.A.; Suresh, A.; Sriram, S.; Ramakrishnan, G.; ·Sadanandham, S.; Veerasamy, M.; Nagalamadaka, R.B.; ·Sahadevan, R. Green synthesis of iron oxide nanoparticles using Hibiscus rosa-sinensis for fortifying wheat biscuits. SN Appl. Sci. 2020,2 , 898. [CrossRef]

23. Wu, Z.; Zhu, W.; Zhang, M.; Lin, Y.; Xu, N.; Chen, F.; Wang, D.; Chen, Z. Adsorption and Synergetic Fenton-like Degradation of Methylene Blue by a Novel Mesoporous $\alpha-\mathrm{Fe} 2 \mathrm{O} 3 / \mathrm{SiO} 2$ at Neutral pH. Ind. Eng. Chem. Res. 2018, 57, 5539-5549. [CrossRef]

24. Stoia, M.; Istratie, R.; Păcurariu, C. Investigation of magnetite nanoparticles stability in air by thermal analysis and FTIR spectroscopy. J. Therm. Anal. Calorim. 2016, 125, 1185-1198. [CrossRef]

25. Chamritski, I.; Burns, G. Infrared- and Raman-Active Phonons of Magnetite, Maghemite, and Hematite: A Computer Simulation and Spectroscopic Study. J. Phys. Chem. B 2005, 109, 11. [CrossRef]

26. De Faria, D.L.A.; Venaüncio Silva, S.; De Oliveira, M.T. Raman Microspectroscopy of Some Iron Oxides and Oxyhydroxides. J. Raman Spectrosc. 1997, 28, 873-878. [CrossRef]

27. Shebanova, O.N.; Lazor, P. Raman spectroscopic study of magnetite (FeFe2O4): A new assignment for the vibrational spectrum. J. Sol. Stat. Chem. 2003, 174, 424-430. [CrossRef]

28. Guin, D.; Manorama, S.V. Room temperature synthesis of monodispersed iron oxide nanoparticles. Mater. Lett. 2008, 62, 3139-3142. [CrossRef]

29. Herrera-Becerra, R.; Rius, J.L.; Zorrilla, C. Tannin biosynthesis of iron oxide nanoparticles. Appl. Phy. A 2010, 100, 453-459. [CrossRef] 
30. Morgan, B.; Lahav, O. The effect of $\mathrm{pH}$ on the kinetics of spontaneous Fe(II) oxidation by $\mathrm{O} 2$ in aqueous solution-basic principles and a simple heuristic description. Chemosphere 2007, 68, 2080-2084. [CrossRef] [PubMed]

31. Pignatello, J.J.; Oliveros, E.; MacKay, A. Advanced Oxidation Processes for Organic Contaminant Destruction Based on the Fenton Reaction and Related Chemistry. Crit. Rev. Environ. Sci. Technol. 2006, 36, 1-84. [CrossRef]

32. Shoniya, T.; Sreekanth, R.; Sijumon, V.A.; Usha, K.A.; Aravinda, K.C.T. Oxidative degradation of Acid Red 1 in aqueous medium. Chem. Eng. J. 2014, 244, 473-482. [CrossRef]

33. Gao, L.; Zhuang, J.; Nie, L.; Zhang, J.; Zhang, Y.; Gu, N.; Wang, T.; Feng, J.; Yang, D.; Perrett, S.; et al. Intrinsic peroxidase-like activity of ferromagnetic nanoparticles. Nat. Nanotechnol. 2007, 2, 577-583. [CrossRef] [PubMed]

34. Tong, J.; Xu, Z.; Bian, Y.; Niu, Y.; Zhang, Y.; Wang, Z. Flexible and smart fibers decorated with Ag nanoflowers for highly active surface-enhanced Raman scattering detection. J. Raman Spectrosc. 2019, 50, 1468-1476. [CrossRef]

35. Jun, B.-M.; Kim, Y.; Yoon, Y.; Yea, Y.; Park, C.M. Enhanced sonocatalytic degradation of recalcitrant organic contaminants using a magnetically recoverable Ag/Fe-loaded activated biochar composite. Ceram. Intern. 2020, 46, 22521-22531. [CrossRef]

36. Lv, Q.; Li, G.; Sun, H.; Kong, L.; Lu, H.; Gao, X. Preparation of magnetic core/shell structured c-Fe2O3@Ti-tmSiO2 and its application for the adsorption and degradation of dyes. Microporous Mesoporous Mater. 2014, 186, 7-13. [CrossRef] 